\title{
A relação entre cultura organizacional e capacidades dinâmicas: uma revisão teórica
}

\section{The relationship between organizational culture and dynamic capabilities: a theoretical review}

\author{
1 Ana Cláudia Wecker anawecker@feevale.br \\ 2 Cristiane Froehlich \\ 3 Vânia Gisele Bessi
}

1 Mestrado em Administração pela Universidade Feevale. Universidade Feevale.

2 Doutora em Administração pela Universidade do Vale do Rio dos Sinos - UNISINOS. Docente do Programa de Pós-Graduação em Administração da Universidade Feevale. Universidade Feevale.

3 Docente do Programa de Pós-Graduação em Administração e do Programa em Indústria Criativa da Universidade Feevale. Universidade Feevale.

\begin{abstract}
Resumo
Com o aumento da competitividade, incertezas e necessidades constantes de mudanças, as empresas buscam sobreviver e se adaptar de acordo com as necessidades de mercado. A cultura organizacional e as capacidades dinâmicas (CDs) são dois aspectos importantes para essa adaptação. 0 presente artigo tem como objetivo verificar a relação entre cultura organizacional e capacidades dinâmicas a partir de uma revisão teórica. Os resultados evidenciaram a seguinte relação: os valores, ações e crenças da liderança influenciam a cultura organizacional, assim como a cultura influencia a liderança, com o decorrer do tempo, através das subculturas e desenvolvimento da empresa. Além disso, a cultura que incentiva aprendizagem, inovação, a assumir riscos e empreendedorismo contribui para o desenvolvimento de capacidades dinâmicas e, por fim, sustenta vantagem competitiva. A principal contribuição do estudo é a apresentação de um framework que conecta as relações identificadas entre cultura organizacional e capacidades dinâmicas.
\end{abstract}

Palavras-chave:

Capacidades Dinâmicas. Cultura Organizacional. Liderança.

\section{Abstract}

With the increase in competitiveness, uncertainties and the constant needs for changes companies seek to survive and adapt according to market needs. Organizational culture and dynamic capabilities (DC) are two important aspects for this adaptation. This article aims to verify the relationship between organizational culture and dynamic capabilities based on a theoretical review. The results showed the following relationship: the values, actions and beliefs of the leadership influence the organizational culture just as the culture influences the leadership over time through the subcultures and development of the company. In addition the culture that encourages learning, innovation, risk-taking and entrepreneurship contributes to the development of dynamic capabilities and, ultimately, sustains competitive advantage. The main contribution of the study is the presentation of a framework that connects the identified relationships between organizational culture and dynamic capabilities.

\section{Keywords:}

Dynamic Capabilities. Organizational culture. Leadership.

Como você deve citar?

WECKER, Ana Cláudia; FROEHLICH, Cristiane; BESSI, Vânia Gisele. A relação entre cultura organizacional e capacidades dinâmicas: uma revisão teórica. Cadernos UniFOA, Volta Redonda (RJ), v. 16, n. 47, p. 53 - 61, dez, 2021. 
Diante de um mercado globalizado, competitivo e caracterizado por mudanças rápidas e constantes, há a necessidade das organizações saberem se adaptar e se manter sustentando vantagem competitiva. A configuração da cultura organizacional é um dos fatores que pode contribuir para essa adaptação da empresa. Segundo Belak, Duh e Milfelner (2016), a cultura organizacional é uma variável-chave, quando se trata de desempenho, flexibilidade, inovação e mudanças no mercado. Gupta (2011) registra que a cultura pode melhorar a produtividade e contribuir para a sustentabilidade de uma organização, desempenho econômico e em seus resultados. Assim, como consequência, pode ser fundamental para o atingimento dos objetivos da organização.

Da mesma forma, diante desse dinamismo do mercado, surge a abordagem sobre capacidades dinâmicas (CDs). Cabe ressaltar que esse conceito ainda está em desenvolvimento e que há várias visões de autores sobre o tema. Segundo Teece (2007), as capacidades dinâmicas estão relacionadas a sentir o contexto do ambiente, aproveitar as oportunidades e gerenciar ameaças e transformações. Na visão de Eisenhardt e Martin (2000), as capacidades dinâmicas são os processos organizacionais e estratégicos que variam e se modificam com o dinamismo do mercado. As diversas definições permitem afirmar que as capacidades dinâmicas podem surgir de diversas formas e, geralmente, estão relacionadas com mudanças no mercado.

Cabe observar que, nos conceitos de cultura organizacional e capacidades dinâmicas, ambos impactam na forma de condução das organizações diante de um mercado competitivo e globalizado. Nesse sentido, apresenta-se o seguinte problema de pesquisa: qual é a relação entre cultura organizacional e capacidades dinâmicas? Sendo assim, por meio de uma revisão teórica, tem-se o objetivo de verificar a relação entre cultura organizacional e capacidades dinâmicas. A partir dessa análise, sugere-se um framework que apresenta os elementos em comum entre os dois temas e a relação entre eles.

A realização deste estudo justifica-se por contribuir com a revisão da literatura, já que há poucos artigos que relacionem os dois temas. Em uma pesquisa realizada em junho de 2020, com o cruzamento de termos "dynamic capabilities" e "organizational culture", dentro das áreas "Negócios, Gestão e Contabilidade", na base de dados do Scopus, foram encontrados 35 trabalhos. Após leitura do resumo desses trabalhos, identificou-se que há relação entre liderança, cultura organizacional e capacidades dinâmicas. A partir disso, foram feitas pesquisas bibliográficas no Scopus e no Google Escolar, com os mesmos termos, analisando-se as relações e verificando-se as características de liderança que influenciam na cultura e de que forma a cultura influencia na liderança. Buscou-se também quais características da cultura contribuem para o desenvolvimento de capacidades dinâmicas, que, por fim, sustentam vantagem competitiva.

\section{CULTURA ORGANIZACIONAL}

O estudo sobre a cultura permite a compreensão dos fenômenos organizacionais, sobretudo pelo aumento da competitividade entre as empresas, mudanças, fusões, aquisições, internalizações, entre outros. Isso se deve pelo fato de ela permear entre os diversos setores e níveis das empresas, exercendo influência, desde o comportamento entre hierarquias e equipes, formulação de estratégias, modo de condução dos negócios, relações com clientes e desempenho organizacional.

Sua origem está fundamentada na Antropologia e na Sociologia. Pettigrew (1979) introduziu esse termo na academia, afirmando que a cultura é um conjunto de significados aceitos por um grupo em um determinado tempo, mostrando a aplicação do estudo nas organizações. Há várias interpretações 
sobre cultura organizacional. Hofstede (1991) defende que a cultura é uma idealização de mentalidade coletiva que diferencia os membros de grupos uns dos outros. Já Fleury e Fischer (1996), afirmam que ela é expressa por meio de símbolos, contribuindo para a construção da identidade e da comunicação organizacional e influenciando as relações de poder.

Para Schein (2009), a cultura organizacional é um conjunto de suposições compartilhadas por um grupo que precisa lidar com a adaptação externa e integração interna, podendo ser ensinados aos novos membros como o modo correto de perceber, pensar e sentir em relação àqueles problemas. Esse autor divide a cultura em artefatos, crenças e valores e pressupostos básicos. Os artefatos são os aspectos fáceis de serem observados e difíceis de serem interpretados. As crenças e valores são as justificativas utilizadas para explicar os atos dos membros da organização. Já os pressupostos básicos, representam o modo como as pessoas sentem, percebem e pensam a organização.

Bass e Avolio (1993) acreditam que a liderança e a cultura organizacional interagem de forma contínua. Schein (2009) tem a mesma percepção, quando relata que o fundador cria e molda a cultura. No entanto, com o desenvolvimento da empresa e a criação de subculturas, a cultura influencia a liderança e molda suas ações e estilo, se tornando um processo cíclico. Para Brown (1992), os bons líderes precisam desenvolver as habilidades que lhes permitam alterar aspectos de sua cultura, a fim de melhorar seu desempenho organizacional.

Schein (2009) registra, em sua obra, sobre a cultura de aprendizagem, propondo uma reflexão de que o mundo será dominado, cada vez mais, por incertezas e constantes e complexas mudanças, havendo a necessidade de organizações e líderes, aprendizes perpétuos. Bates e Khasawneh (2005) enfatizam que esse tipo de cultura possui fins criativos em prol das metas. Também é válida na busca de inovação e desempenho em ambientes dinâmicos.

A cultura vem sendo cada vez mais considerada uma variável crítica para o atingimento de objetivos. Diante de um mercado competitivo e repleto de mudanças, sua compreensão e configuração podem contribuir para a obtenção de capacidades dinâmicas, tema a ser abordado na próxima seção.

\section{CAPACIDADES DINÂMICAS (CDS)}

Com as constantes mudanças no meio empresarial, pode-se observar a crescente relevância que a abordagem de capacidades dinâmicas adquiriu nos últimos anos. Barreto (2010) defende que, embora haja alguns estudos anteriores, foi após a publicação do artigo Dynamic Capabilities and Strategic Management, de Teece, Pisano e Shuen (1997) que ocorre a evolução na pesquisa sobre o tema. Esses autores destacam que o conceito de CDs está associado "à habilidade de integrar, construir e reconfigurar competências internas e externas em resposta às rápidas mudanças que ocorrem nos ambientes" (TEECE; PISANO; SHUEN, 1997, p. 516). Para eles, as CDs e a vantagem competitiva são baseadas em: processos, posições e trajetória (TEECE; PISANO; SHUEN, 1997).

Cabe ressaltar que há diferentes visões sobre o tema. Geralmente, cada autor enfatiza algum aspecto do conceito. Helfat et al. (2007) se referem à capacidade da organização criar, estender ou modificar sua base de recursos. Zollo e Winter (2002) defendem que são as capacidades para operar, estender, modificar ou criar capacidades comuns, se preocupando com a mudança. Wang e Ahmed (2007) remetem a integrar, reconfigurar, renovar e recriar os recursos e capacidades da empresa e, ainda, melhorar e reconstruir capacidades diante das mutações do ambiente, para atingir e sustentar a vantagem competitiva. Eles destacam que, em um ambiente de grandes mudanças, é necessário alterar e atualizar suas competências para desenvolver um nível mais alto de capacidades dinâmicas. 
Em 2007, Teece apresentou um novo conceito, no qual as capacidades dinâmicas são sustentadas por microfundamentos, sendo eles: sensing, ou seja, detectar e moldar oportunidades e ameaças; seizing, que se refere a aproveitar as oportunidades; e reconfiguring, definido como recombinar e reconfigurar ativos e estruturas organizacionais (TEECE, 2007).

Em ambientes de incerteza, é importante imaginar o futuro e tentar construí-lo. Teece e Leih (2016) registram que, com as capacidades dinâmicas, as empresas tendem a ter mais tempo para responder a choques positivos e negativos. Wang et al. (2019) reforçam que muitas empresas perdem oportunidades de desenvolvimento, devido à falta de atenção real às mudanças ambientais. Teece (2007) complementa abordando que a cultura precisa ser moldada para que as mudanças internas sejam aceitas, sendo esta uma importante responsabilidade da liderança. A seguir, apresenta-se a análise da relação entre a cultura organizacional e capacidades dinâmicas.

\section{A RELAÇÃO ENTRE CULTURA ORGANIZACIONAL E CAPACIDADES DINÂMICAS}

A partir da revisão de literatura sobre os dois temas, é possivel verificar que determinados tipos de culturas contribuem para o desenvolvimento de capacidades dinâmicas, sendo que o estilo de liderança influencia na cultura e, por consequência, contribui ou não para a construção de capacidades dinâmicas. A seguir, tais relações são abordadas.

No estudo de Peng e Lin (2017), os autores abordam sobre a cultura organizacional com orientação para o mercado e para a aprendizagem que contribui para o desenvolvimento de capacidades dinâmicas. A primeira favorece a empresa no acesso a informações de mercado, de forma que ela implemente estratégias de marketing e tome decisões de desenvolvimento de produtos com mais precisão. Já a segunda, se concentra na aquisição, assimilação, transformação e aplicação de conhecimentos internos, além de facilitar a interpretação compartilhada do conhecimento, aumentar a eficiência e a velocidade do desenvolvimento de rotinas organizacionais dentro da empresa e reforçar os esforços empreendedores.

Da mesma forma, Gonzalez e Melo (2017) defendem que a gestão do conhecimento contribui para o estímulo ao processo criativo e incentiva a experimentação de novas alternativas para a solução de problemas. Assim, a cultura de aprendizado contribui para o desenvolvimento de capacidades dinâmicas, gerando inovação, através da adaptação e empreendedorismo. Liang et al. (2020) complementam que as empresas com CDs tendem a ter uma cultura empreendedora, envolvendo aprendizado, aprimoramento e inovação.

Para Schein (2009), oganizações com cultura de aprendizagem têm maior facilidade para adquirir informações, interpretar e entender os significados e, por fim, transformá-los em novos conhecimentos e insights. Vale ressaltar que mudanças comportamentais e cognitivas são importantes para transformar os conhecimentos em ações. Sobre isso, Kalyar e Rafi (2013) enfatizam que nesse tipo de cultura, os líderes devem contribuir para o direcionamento e entendimento dos objetivos e ambiente no qual a organização está inserida.

Em um estudo com uma empresa de tecnologia chinesa, Liang et al. (2020) abordam sobre a necessidade das capacidades dinâmicas em um ambiente altamente competitivo. Nessa pesquisa, os autores buscam entender as forças que impulsionam as CDs e concluem que a liderança visionária influencia a cultura de aprendizado, a inovação e as políticas estratégicas de recursos humanos, que, por sua vez, criam e atualizam coletivamente os recursos operacionais para oferecer vantagens competitivas. Esse tipo de líder possui visão de longo prazo, inspira os membros a manter o alto padrão, mobiliza os funcionários para aprendizagem e mudanças e possuem facilidade de adaptação ao ambiente. Assim, a cultura voltada para a aprendizagem e mudanças contribui para o desenvolvimento das capacidades dinâmicas. 
Teece (2007) aborda sobre a importancia do líder para os microfundamentos que sustentam as capacidades dinâmicas: sensing, seizing e reconfiguring, já que ele possui uma função importante na identificação de oportunidades, na direção para o negócio e na reconfiguração dos recursos, em ambientes de rápidas mudanças. Nos estudos de Evans e Salaiz (2019), os autores registram que, para manter a capacidade de detectar, apreender e reconfigurar oportunidades, os funcionários devem ser expostos a esse tipo de cultura com incentivo a identificação de oportunidades, novas ideias, treinamentos e projetos. É importante envolvê-los em processos que contribuam para a experiência em tomadas de decisões, para que, através das práticas e diante da imprevisibilidade do mercado, o funcionário já saiba como agir.

Na pesquisa sobre estilo cognitivo de gerentes, cultura e capacidades dinâmicas, Krupski e Grynko (2018) identificam que o estilo cognitivo impacta nas capacidades dinâmicas e que a cultura exerce um papel moderador entre ambos. Um maior grau de centralização, por exemplo, permite que os gerentes tenham um impacto maior nos processos organizacionais. Além disso, quando a cultura está bem disseminada, as rotinas dinâmicas funcionam mais eficientemente e, assim, a empresa consegue se adaptar melhor em ambientes de mudanças.

Shamima et al. (2019) analisam as influências no gerenciamento de big data para a tomada de decisão e, entre os fatores estudados, a cultura organizacional é o que tem a associação mais forte com a capacidade de tomada de decisão. Para detectar e aproveitar as oportunidades, a cultura deve ser orientada para mudanças, aprendizagem, experimentação e tolerância a riscos. Assim, eles concluem que o gerenciamento através de big data é importante para desenvolver e reconfigurar capacidades dinâmicas.

Considerando a revisão teórica, propõe-se um framework, que contempla as relações entre cultura organizacional e capacidades dinâmicas:

Figura 1: A relação entre liderança, cultura organizacional e capacidades dinâmicas

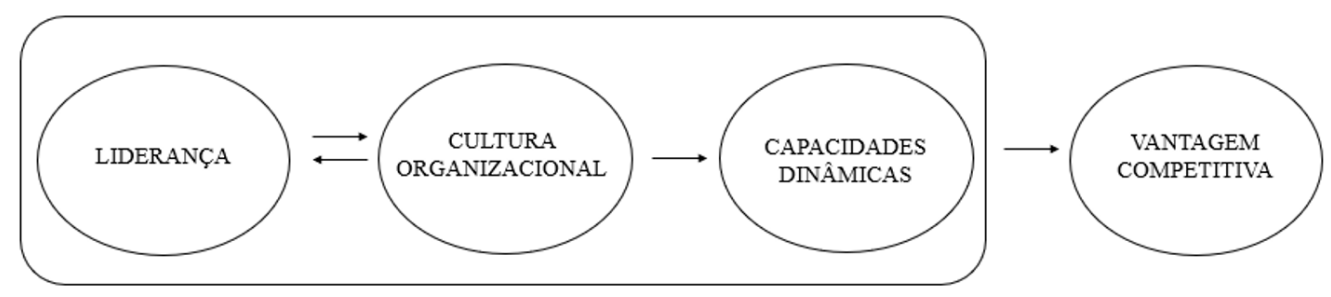

Fonte: elaborada pelas autoras.

A partir dessa estrutura, tem-se o entendimento de que a liderança impacta na cultura organizacional com suas ações, crenças e estilo, assim como a cultura influencia a liderança, com o decorrer do tempo e desenvolvimento da empresa, tornando-se um processo contínuo. A seguir, apresenta-se um quadro síntese com os principais autores que relacionam os temas. 
Quadro 1: Relação entre Liderança, Cultura e CDs - principais autores

\begin{tabular}{|l|l|}
\hline \multirow{4}{*}{ Temas relacionados } & Principais atores \\
\hline \multirow{4}{*}{ Liderança e Cultura Organizacional } & Barreto (2013) \\
\cline { 2 - 2 } & Block (2003) \\
\cline { 2 - 2 } & Kalyar e Rafi (2013) \\
\cline { 2 - 2 } Cultura Organizacional e Capacidades Dinâmicas & Schein (2009) \\
\hline \multirow{2}{*}{ Capacidades Dinâmicas e Vantagem Competitiva } & Peng e Lin (2017) \\
\hline \multirow{4}{*}{$\begin{array}{l}\text { Liderança, Cultura Organizacional e Capacidades } \\
\text { Dinâmicas }\end{array}$} & Liu (2005) \\
\cline { 2 - 2 } & Teece (2007) \\
\cline { 2 - 2 } & Evans e Salaiz (2019) \\
\cline { 2 - 2 } & Krupski e Grynko (2018) \\
\cline { 2 - 2 } & Liang et al. (2020) \\
\cline { 2 - 2 } & Shamina et al. (2019) \\
\hline
\end{tabular}

Fonte: elaborado pelas autoras.

Barreto et al. (2013, p. 39) comentam sobre a cultura: "surge e muda em virtude de onde os líderes focam suas atenções, de como reagem a crises, de quais sejam seus modelos de comportamentos e de quem eles atraem para suas organizações". Assim, a liderança influencia as características da cultura organizacional, pois, sejam intencionais ou não, suas ações e atitudes afetam as ações da equipe. 0 líder emprega suas características pessoais, como autoconfiança, convicções, formas de comunicação, entre outros.

Além disso, a cultura pode ser modificada com o decorrer do tempo, com as crenças, ações e visões das pessoas dentro da empresa. Os subgrupos ou subculturas envolvem a própria cultura e produzem uma nova cultura e, dessa forma, influenciam as lideranças. Para Block (2003, p. 331), "os supervisores imediatos são os principais agentes culturais na organização. Se o executivo sênior fornece a visão, o supervisor é o tradutor dessa visão para seus funcionários, tanto em palavras quanto em ações", ou seja, é necessário atentar para a distância entre líderes e liderados, em relação à quantidade de níveis hierárquicos.

Da mesma forma, os tipos de culturas organizacionais influenciam a obtenção de capacidades dinâmicas, ou seja, a cultura voltada para o mercado, aprendizagem, inovação e empreendedorismo contribui para o desenvolvimento das CDs e, como consequência, a empresa obtém vantagem competitiva para sobrevivência no mercado, como, por exemplo, empresas com cultura de aprendizagem questionam rotinas e crenças, criam e disseminam conhecimentos e facilitam a adaptação às mudanças. Nessa perspectiva, Liu (2005) afirma que a vantagem competitiva pode ser construída pelas capacidades dinâmicas, por meio de procedimentos de obtenção de conhecimento. A cultura que enfatiza o aprendizado e a inovação reforça a capacidade de empreender, facilita a interpretação de conhecimentos e contribui para a transformação de recursos, impulsionando o desenvolvimento de capacidades dinâmicas, que são fontes de vantagem competitiva.

\section{CONSIDERAÇÕES FINAIS}

Este artigo teve como objetivo verificar a relação entre cultura organizacional e capacidades dinâmicas a partir de uma revisão teórica. Nesse sentido, observou-se que a liderança influencia a cultura organizacional, assim como a cultura impacta na liderança. A cultura pode refletir no desenvolvimento das capacidades dinâmicas, que, por sua vez, sustentam vantagem competitiva. 
Através de seu poder e autoridade, o líder direciona a empresa para a consecução de metas e objetivos e direcionam a cultura de acordo suas ações, seu estilo de liderar, suas crenças e vivências. Nesse sentido, criam mecanismos e regras, definem estruturas, sistemas e procedimentos, reagindo ao ambiente de acordo com seus valores. Além disso, são responsáveis pela contratação e desenvolvimento de pessoas que farão parte daquele ambiente, contribuindo para a formação da cultura organizacional.

Pode-se afirmar, ainda, que o líder é influenciado pela cultura com o decorrer do tempo. Dentro de uma organização, pode haver subculturas formadas pelos grupos que produzem novas culturas que impactam nas lideranças. Da mesma forma, quanto mais distante os líderes estiverem de suas equipes, menor será sua influência.

Conclui-se que o tipo de cultura contribui para o desenvolvimento de capacidades dinâmicas, que, quando voltadas para o aprendizado, favorecem o acesso às informações de mercado, incentivam a criatividade e a colaboração, possibilitam a aplicação dos conhecimentos obtidos, gerando novas ideias e reforçando o empreendedorismo. Esse tipo contribui para a adaptação dos funcionários diante de um ambiente de mudanças e colabora para a construção de capacidades dinâmicas.

A literatura sobre CDs aponta que, à medida que ocorrem mudanças no ambiente, as empresas detectam, aproveitam oportunidades e reconfiguram seus recursos. Esse tipo de processo está vinculado às decisões sobre como alocar este último componente, como construir lealdade e comprometimento dos funcionários e como gerenciar ameaças e transformações. Por meio desse gerenciamento contínuo, fundamental para lidar com mudanças, a empresa obtém e sustenta vantagem competitiva.

Este estudo contribui para literatura, uma vez que há poucos trabalhos relacionando os temas cultura organizacional e capacidades dinâmicas. Além disso, fornece informações para as empresas com estilos de lideranças e culturas mais adequadas para o desenvolvimento das CDs. Para a realização de pesquisas futuras, sugere-se a aplicação de estudos empíricos, analisando-se empresas com diferentes tipos de culturas e suas respectivas contribuições para o desenvolvimento das capacidades dinâmicas.

\section{REFERÊNCIAS}

Ambrosini, V., \& Bowman, C. (2009). What are dynamic capabilities and are they a useful construct in strategic management? International Journal of Management Reviews, 11(1), 29-49.

BARRETO, llídio. Dynamic capabilities: A review of past research and an agenda for the future. Journal of management, v. 36, n. 1, p. 256-280, 2010.

BARRETO, Leilianne Michelle Trindade da Silva et al. Cultura organizacional e liderança: uma relação possível?. Revista de Administração, v. 48, n. 1, p. 34-52, 2013.

BASS, Bernard M.; AVOLIO, Bruce J. Transformational leadership and organizational culture. Public administration quarterly, p. 112-121, 1993.

BATES, Reid; KHASAWNEH, Samer. Organizational learning culture, learning transfer climate and perceived innovation in Jordanian organizations. International journal of training and development, v. 9, n. 2, p. 96-109, 2005.

AMBROSINI, V.; BOWMAN, C. What are dynamic capabilities and are they a useful construct in strategic management? Internacional Journal of Management Reviews, v. 11, n. 1, p. 29-49, 2009. 
BELAK, Jernej et al. Culture and Dynamics of an Enterprise. In: Proceedings-10th International Conference on Mangement, Enterprise and Benchmarking (MEB 2012). Óbuda University, Keleti Faculty of Business and Management, p. 9-18, 2012.

BLOCK, Lory. The leadership-culture connection: an exploratory investigation. Leadership \& Organization Development Journal, 2003.

BROWN, Andrew. Organizational culture: The key to effective leadership and organizational development. Leadership \& Organization Development Journal, 1992.

CAMERON, Kim S.; QUINN, Robert E. Diagnosing and changing organizational culture: Based on the competing values framework. John Wiley \& Sons, 2011.

EISENHARDT, Kathleen M.; MARTIN, Jeffrey A. Dynamic capabilities: what are they?. Strategic management journal, v. 21, n. 10-11, p. 1105-1121, 2000.

EVANS, Klavdia Markelova; SALAIZ, Ashley. Sensing opportunities in dynamic markets: how to encourage all employees to take part. Journal of Business Strategy, 2019.

FLEURY, M. T., FISCHER, R. M. Cultura e Poder nas Organizações. São Paulo: Atlas, 1996.

GONZALEZ, Rodrigo Valio Dominguez; MELO, Tatiana Massaroli. Linkage between dynamics capability and knowledge management factors. Management Decision, 2017.

GUPTA, Bindu. A comparative study of organizational strategy and culture across industry. Benchmarking: An International Journal, 2011.

HELFAT, Constance E. et al. Dynamic capabilities: Understanding strategic change in organizations. John Wiley \& Sons, 2009.

HOFSTEDE, Geert. Culture and Organizations: software of the mind. New York: McGraw-Hill, 1991.

KRUPSKYI, Oleksandr P.; GRYNKO, Tetiana. Role of cognitive style of a manager in the development of tourism companies' dynamic capabilities. Tourism and Hospitality Management, v. 24, n. 1, p. 1-21, 2018.

LIANG, Xin et al. How did a local guerrilla turn into a global gorilla? Learning how transformational change happened under dynamic capabilities from the rise of Huawei. Journal of Organizational Change Management, 2020.

PENG, Yao-Ping; LIN, Ku-Ho. The effect of global dynamic capabilities on internationalizing SMEs performance. Baltic Journal of Management, 2017.

PETTIGREW, Andrew M. On studying organizational cultures. Administrative science quarterly, v. 24, n. 4, p. 570-581, 1979.

SCHEIN, Edgar H. Cultura organizacional e liderança. Rio de Janeiro: Atlas, 2009.

SHAMIM, Saqib et al. Role of big data management in enhancing big data decision-making capability and quality among Chinese firms: A dynamic capabilities view. Information \& Management, v. 56, n. 6, p. 1031-1035, 2019. 
TEECE, D. J.; PISANO, G.; SHUEN, A. Dynamic capabilities and strategic management. In: FOSS, N. J. (Ed.). Resources firms and strategies - a reader in the resource-based perspective. Oxford: Oxford University Press, p. 268-285, 1997.

TEECE, David J. Explicating dynamic capabilities: the nature and microfoundations of (sustainable) enterprise performance. Strategic management journal, v. 28, n. 13, p. 1319-1350, 2007.

TEECE, David; LEIH, Sohvi. Uncertainty, innovation, and dynamic capabilities: An introduction. California Management Review, v. 58, n. 4, p. 5-12, 2016.

ZOLLO, Maurizio; WINTER, Sidney G. Deliberate learning and the evolution of dynamic capabilities. Organization science, v. 13, n. 3, p. 339-351, 2002.

WANG, Catherine L.; AHMED, Pervaiz K. Dynamic capabilities: A review and research agenda. International journal of management reviews, v. 9, n. 1, p. 31-51, 2007.

WANG, Wenke et al. Uncertain environment, dynamic innovation capabilities and innovation strategies: A case study on Qihoo 360. Computers in Human Behavior, v. 95, p. 284-294, 2019. 